\title{
Study of aqueous and non-aqueous phase liquid in fractured double-porosity soil using digital image processing
}

\author{
Loke Kok Foong ${ }^{1}$, Norhan Abd Rahman $^{2}$, Ramli Nazir ${ }^{2}$ and Roland W Lewis ${ }^{3}$ \\ 1 Universiti Teknologi Malaysia, Faculty of Civil Engineering, Johor, Malaysia; (edwinloke84@yahoo.com) \\ 2 Universiti Teknologi Malaysia, Centre of Tropical Geoengineering, Faculty of Civil Engineering, Johor, Malaysia \\ ${ }^{3}$ University of Wales Swansea, School of Engineering, Swansea, W. Glam, SA2 8PP, United Kingdom
}

doi: $10.4154 / g c .2018 .12$

Article history:

Manuscript received December 19, 2017 Revised manuscript accepted April 27, 2018 Available online June 21, 2018

Keywords: groundwater pollution, fracture porous media, saturation, liquid migration, digital image analysis.

\begin{abstract}
The leakage and spillage of non-aqueous phase liquids (NAPLs) and aqueous phase liquids (APLs) contribute to groundwater contamination, resulting in groundwater pollution and rendering the quality of groundwater unsafe for drinking and agriculture. Ensuring the availability and sustainable management of water and sanitation for all was the goal and target of the 2030 United Nations agenda for sustainable development, consisting of a plan of action for the population, the planet and general prosperity. This paper is intended to investigate the aqueous and nonaqueous phase liquid migrations in a deformable double-porosity soil, which has become important for both sustainable groundwater use and the comprehensive understanding of the behaviour of liquid migration into groundwater. A modelling experiment was conducted in an attempt to study the pattern and behaviour of aqueous and non-aqueous phase liquid migration in fractured double-porosity soil using a digital image processing technique. The results of the experiments show that the flow of the APL and NAPL migration was not uniformly downward. Faster migration occurred where the soil surface was cracked compared to other locations where the soil surface was not cracked, even when liquids such as toluene were not used. It was concluded that the factors that significantly influenced the APL and NAPL migration were the structure of the soil sample, fracture pattern of the soil sample, physical interaction i.e. bonding between the liquid and soil sample, and the capillary pressure of the fluid. This study indicates that digital image analysis can provide detailed information to help researchers better understand and be able to simulate the pattern and characteristics of liquid migration that have an influence on groundwater resources.
\end{abstract}

\section{INTRODUCTION}

Natural disasters such as flash flooding, earthquakes, groundwater contamination and climate change have had an influence on national development activity, which has led to a negative impact on human health and the geo-environment. Groundwater contamination is one of the most challenging geo-environmental issues encountered in many countries, resulting in rendering the quality of groundwater unsafe for consumption and agriculture (YOUSEF et al., 2015). More complicated problems arise when the surface, or subsurface, has experienced an earthquake vibration, which then influences the migration of APL and NAPL into groundwater sources. Vibration leads to the rearrangement of the soil structure resulting in the development of an unstable soil structure, cracked soil, and volumetric deformation of soil aggregate structures, all of which can create problems that affect the characteristic pore sizes of the soils (LOKE et al., 2017). These problems need to be overcome to ensure the sustainability of groundwater resources and the geo-environment.

Multiple porosity soil models have been widely used to characterize soil with different pore sizes and hydraulic properties (NGIEN et al., 2011). However, this requires further investigation especially with respect to a fractured soil condition and contaminant transport. The danger of releasing toxic chemicals means that on-site real-time studies are not feasible and have been replaced by physical experimental simulations and modelling. The most serious contaminants include petroleum hydrocarbons such as toluene, which can be classified as a type of liquid with a den- sity less than that of water. Toluene is known as a light non-aqueous phase liquid (LNAPL), and has been used in this study as a proxy for other hydrocarbon liquids.

The structure of the soil affects the speed, rate, and pattern of liquid migration. Under natural conditions, soil is typified by many different structures and hence is not a homogeneous medium. Cracked soil increases the hydraulic conductivity and reduces the soil shear strength (FREDLUND et al., 2010). Research by KRISNANTO et al. (2014) recognizes that fractured soil played an essential role in influencing the flow of liquids through problematic soil structures. In the same way, FREDLUND et al. (2010) stated that the mechanical properties and hydrological characteristics in cracked soils are significantly different. The term "double-porosity" refers to soil that displays two specific scales of porosity (CARMINATI et al., 2008). Double-porosity soil displays a pore-size bimodal distribution due to the conditions of intra-aggregate and inter-aggregate pores, which can be found in agricultural topsoil's and compacted soil (LI \& ZHANG, 2009; EL-ZEIN et al., 2006). Using first principles analysis, LAKELAND et al. (2014) verified that liquefaction is not a strictly undrained process. In fact, the interplay between soil rearrangement, permeability changes, and liquid migration leads to a loss of strength as detected in numerous examples of destructive earthquake situations. Furthermore, MASCIOPINTO et al. (2001) demonstrated that fractured porosity formations were characterized by water-bearing formations where groundwater flows along fissures and fractures in the solid rock. The fractures 
were a result of a fracture of the rock mass caused by tectonic forces, which is also known as an earthquake force.

The dual-continuum method is more capable of dealing with a fracture-matrix interplay compared to the discrete-fracture model (FREDLUND et al., 2010). Therefore, this study applied the model concept of a fractured double-porosity medium with the soil that overlaps the three continuums. These consist of fracture porosity, primary porosity and secondary porosity features as developed by LOKE et al. (2016). According to LEWANDOWSKA et al. (2005), the double-porosity characteristics in soil could be generated in the laboratory, where most studies concerning double-porosity soil are carried out. Furthermore, BAGHERIEH et al. (2009) conducted a series of one-dimensional drying and consolidation experiments on laboratory-prepared aggregated kaolin samples. Recently, a number of researchers (ALAZAIZA et al., 2017; SITTHIPHAT \& SIAM, 2016; NGIEN et al., 2016; SA'ARI et al., 2015; PENG et al., 2015) have conducted experiments on double-porosity soil media that have contributed to the body of knowledge and understanding of soil characteristics. However, to the best of our knowledge, these studies were limited to the common intact double-porosity method and the effect of vibration imposed onto the double-porosity soil method was not implemented. Based on the above, this experimental study uses kaolin soil to produce double-porosity soil characteristics in the laboratory. In Malaysia, natural kaolin soil could be found in many states such as Perak, Johor, Pahang, Selangor, Terengganu, Kelantan, Sabah and Sarawak (SEONG, 2005).

A powerful method used in many research areas is the image analysis method, which is used to investigate the complicated characteristics of contaminants and to determine the liquid saturation rate (LUCIANO et al., 2010). Therefore, this study used digital image analysis to understand and analyse the APL and NAPL migration in a fractured double-porosity soil. Digital image analysis is a mode of analysis using a computer to obtain information and data from a digital image. The common ways to observe and monitor liquid migration involve many measuring apparatuses that may interfere with the original sample setup; however, using digital image processing techniques will overcome the problem using non-destructive and non- intrusive techniques. CNUDDE \& BOONE (2013) found that image analysis is a reliable technique for the direct investigation and imaging of liquid migration in rock pore space. In this case, numerous researchers (ALAZAIZA et al., 2017; NGIEN et al., 2016; ZHENG et al, 2015; BOB et al., 2008; KECHAVARZI et al., 2008; BRIDGE et al., 2007) have conducted non-intrusive image techniques for physical experiments in liquid migration analysis. Porous and cracked soils are very hard to monitor with the naked eye, and for this reason, digital image processing analysis was suitable and acceptable for use in the study of the migration of liquids in fractured double-porosity soil.

The difficult problem of gathering data concerning immiscible liquid movement characteristics and the appropriate physical experiments will help in the effort to comprehensively understand, monitor, observe, evaluate and solve groundwater contaminant problems (NGIEN et al., 2012). Recent research by KRISTNANTO et al. (2014) demonstrated the significance of understanding the flow behaviour through a cracked soil and suggested that further experimental studies on more complex crack patterns to investigate the liquid speed rate were required. Therefore, a physical experimental model was conducted to study the characteristics of APL and NAPL migration in deformable dou- ble-porosity soil under the effects of vibration, by using digital image analysis. This study attempts to bridge the gap with the following objectives (i) to determine the behaviour of APL and NAPL migration in a fractured double-porosity soil using a digital image processing technique, (ii) to differentiate the pattern between APL and NAPL migration in fractured double-porosity soil, and (iii) to identify the APL and NAPL migration rate for a specific soil column circumference zone in the soil sample.

\section{MATERIALS AND METHODS}

In this study, details of the fracture double-porosity soil sample preparation, experimental setup and digital image processing setup are discussed in the following subsections.

\subsection{Fracture double-porosity soil sample preparation}

A commercially available artificial kaolin soil type S300 was used as the soil sample in this study to produce a double-porosity model. Double-porosity displays the condition of intra-aggregate and inter-aggregate pores with different hydraulic properties in aggregated soil (MAJA et al., 2015). The kaolin soil properties were tested based on British Standards BS1377-2: 1990 and BS1377-5: 1990 for the purpose of acquiring particle size distribution, Atterberg limits, saturated permeability and soil particle density of the kaolin soil. The kaolin soil S300 properties are shown in Table 1.

The aggregated kaolin soil was prepared based on the method of LOKE et al. (2017) and BAGHERIEH et al. (2009), where the dried kaolin powder was first mixed with water to produce a $25 \%$ moisture content for samples 1 and 2 . Distilled water is constantly poured when mixing the dried kaolin powder to control the moisture content within the mixture. The optimum moisture content for a kaolin S300 soil sample is $27 \%$, whereas a $25 \%$ moisture content was chosen for this study. This is because the $25 \%$ moisture content was mouldable and not too wet to form the aggregate, while with a moisture content less than $25 \%$, the kaolin was unable to form aggregates because the kaolin granules were too crumbly and dry (NGIEN et al., 2016). Thereafter, the mixture was kept in a plastic bag to maintain the moisture content, and left to cure in cool conditions for a minimum of 24 hours in order to attain water content equilibrium. After the process of curing, the mixture was passed through a $2.36 \mathrm{~mm}$ sieve to obtain kaolin granules for the purpose of creating the double-porosity soil structure. The kaolin granules with a weight of $0.97 \mathrm{~kg}$ were placed in an acrylic soil column and compressed to a height of $100 \mathrm{~mm}$ using a compaction machine at a compression rate of $1 \mathrm{kgf} / \mathrm{cm}^{2}$. The sample height of $100 \mathrm{~mm}$ was chosen to ensure uniformity throughout the soil sample depth.

Experiments were conducted on an acrylic soil column sealed base with dimension of $300 \mathrm{~mm}$ high $\times 100 \mathrm{~mm}$-outer di-

Table 1. Kaolin soil S300 properties.

\begin{tabular}{ll}
\hline PROPERTY & VALUE \\
\hline Liquid Limit (\%) & 40.50 \\
Plastic Limit (\%) & 27.00 \\
Plasticity Index (\%) & 13.50 \\
Particle Density $\left(\mathrm{Mg} / \mathrm{m}^{3}\right)$ & 2.65 \\
Sand: $2 \mathrm{~mm}$ to $0.06 \mathrm{~mm}(\%)$ & 3 \\
Silt: $0.06 \mathrm{~mm}$ to $0.002 \mathrm{~mm}(\%)$ & 93 \\
Clay: Smaller than 0.002mm (\%) & 4 \\
USCS Classification & $\mathrm{ML}$ \\
Saturated Permeability, $\mathrm{K}_{\text {average }}(\mathrm{m} / \mathrm{s})$ & $5.41 \times 10^{-9}$ \\
\hline
\end{tabular}




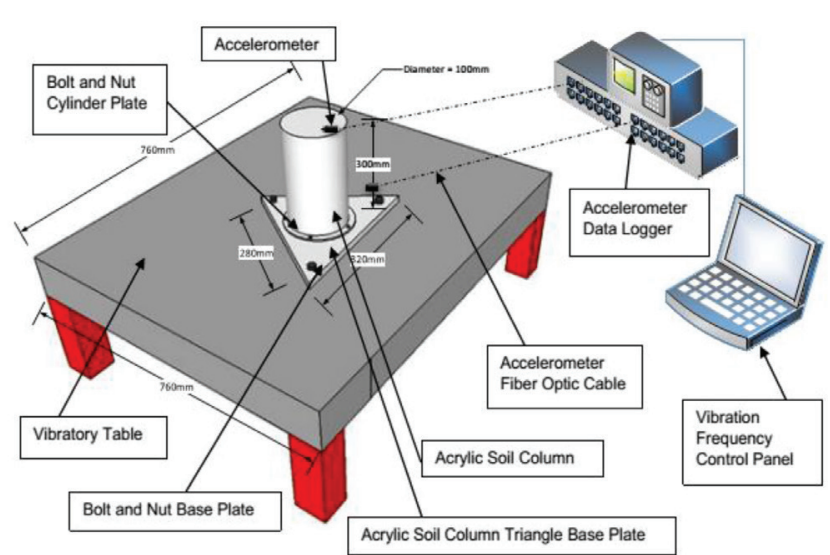

Figure 1. Vibration table setup (LOKE et al., 2016).

ameter and 94 mm-inner diameter. The acrylic soil column has been custom designed to monitor and detect the phenomena occurring inside the whole area of the circular column. The acrylic soil column with kaolin granular "soil" was fixed and bolted onto the vibration table in order to prevent any random movement of the soil column during the vibration process. The setup of the vibration table used in the experiment was developed by LOKE et al. (2016) as shown in (Fig. 1).

Moderate to low seismic activity, such as the magnitude 6.0 earthquake that struck Ranau, Malaysia on 5 June 2015 around 7:15 am is one of the examples used. This earthquake had a peak ground acceleration of $0.12 \mathrm{~g}$ (HARITH et al., 2017). Thus, based on the details, seismic activity and SeismoSignal software analysis display an approximate vibration frequency of only $0.95 \mathrm{~Hz}$. Therefore, a vibration frequency $0.98 \mathrm{~Hz}$ was adopted for this study. The double-porosity soil samples with $25 \%$ moisture content were placed on the vibration table and subjected to vibration frequencies following the loading protocol outlined by FEMA 461 (2007). The vibration frequency for the vibration table was
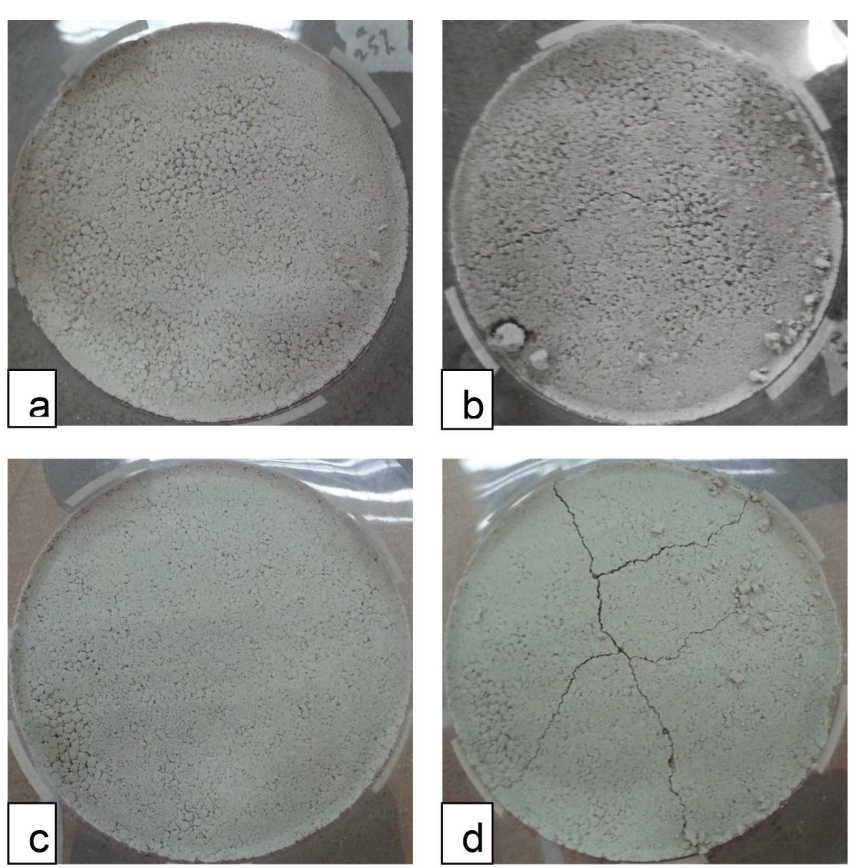

Figure 2. a) Soil sample 1 before vibration process. b) Soil sample 1 after vibration process with fracture. c) Soil sample 2 before vibration process. d) Soil sample 2 after vibration process with fracture.
Table 2. Image acquisition frequency.

\begin{tabular}{lcc}
\hline DURATION (Min) & \multicolumn{2}{c}{ FREQUENCY INTERVAL $(\mathrm{s})$} \\
\hline $0-2$ & SAMPLE 1 & SAMPLE 2 \\
\hline $2-4$ & $3 \mathrm{~s}$ & $3 \mathrm{~s}$ \\
$4-6$ & $5 \mathrm{~s}$ & $5 \mathrm{~s}$ \\
$6-8$ & $10 \mathrm{~s}$ & $10 \mathrm{~s}$ \\
$8-9$ & $15 \mathrm{~s}$ & $15 \mathrm{~s}$ \\
$9-10$ & $20 \mathrm{~s}$ & $20 \mathrm{~s}$ \\
$10-20$ & $30 \mathrm{~s}$ & $30 \mathrm{~s}$ \\
$20-30$ & $60 \mathrm{~s}$ & $60 \mathrm{~s}$ \\
$30-40$ & $60 \mathrm{~s}$ & $60 \mathrm{~s}$ \\
\hline
\end{tabular}

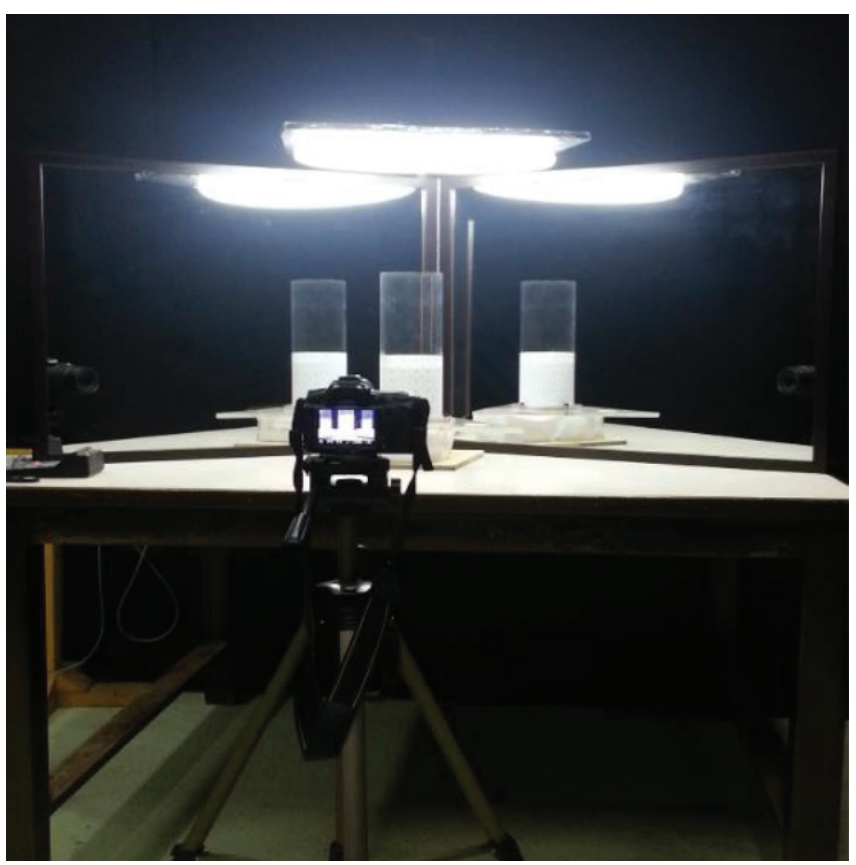

Figure 3. Digital image acquisition experiment setup.

set at a $0.98 \mathrm{~Hz}$ frequency and the vibration process duration was 60 seconds. This was twice as long as the 30 seconds real-time earthquake in order to simulate the worst case scenario based on the method and setup given by LOKE et al. (2016). The results of the fractured soil patterns before and after the vibration process for samples 1 and 2 (25\% moisture content) are displayed in (Fig. 2). The soil samples clearly display fracturing in the top region of the soil. Thus, the concept of a fracture double-porosity phenomenon was to prove that in fact the vibration effect had caused the double-porosity soil to fracture.

\subsection{Experimental setup}

The fractured double-porosity in the soil column was used to measure and monitor the LNAPL and water migration inside the whole circular column area with the aim of simulating groundwater contamination. The simulation did not interfere with the original soil sample as a digital image processing technique was used. In each sample, the experiment setup was arranged as shown in (Fig. 3) for APL and NAPL migration image acquisition.

A Nikon D90 Digital Single Lens Reflex (DSLR) camera was used for fluid migration image acquisition and the $\mathrm{V}$ shape reflection mirror was used to reflect the whole area of soil column image. The camera is equipped with a sensor size of $23.6 \mathrm{~mm} \mathrm{x}$ 


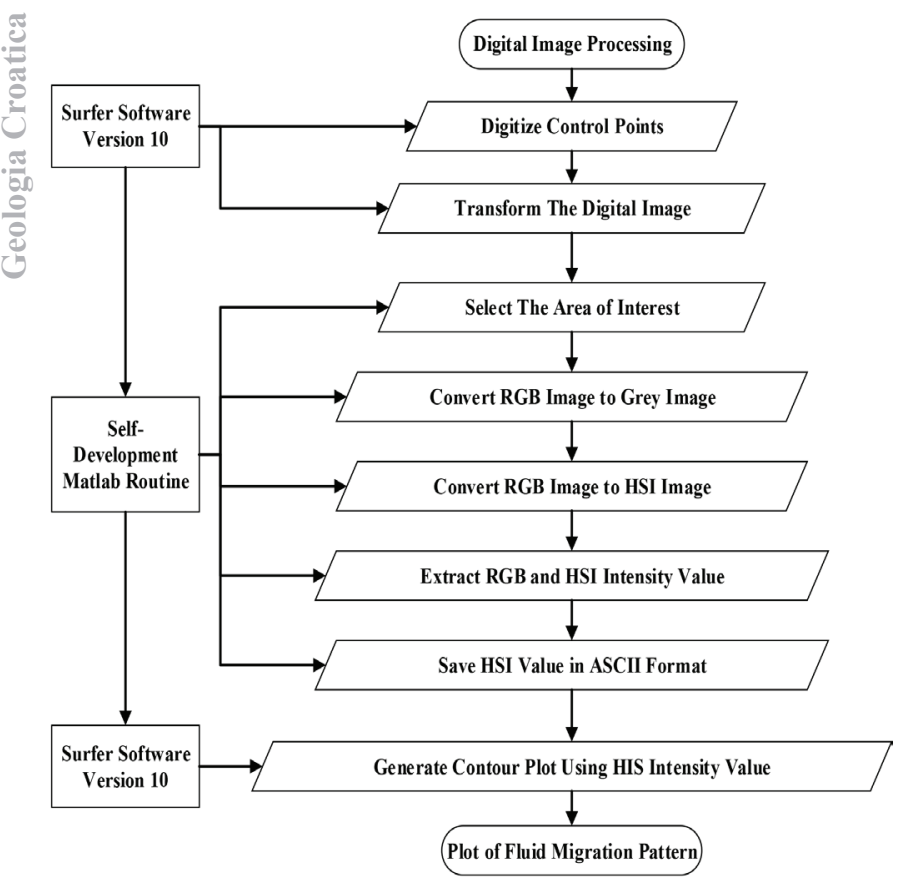

Figure 4. The flow chart of digital image processing method.

$15.8 \mathrm{~mm}$ and a medium size image format of $3216 \times 2136$ pixels was used resulting in each pixel having the size resolution of $5.6 \mu \mathrm{m} \times 5.6 \mu \mathrm{m}$. The camera, which also had a remote control, was used to capture images smoothly without vibration of the camera. The V shape mirror was set and adjusted until a clear image that allowed $100 \%$ of the soil column to be achieved. The experimental light source came from a linear fluorescent lamp40 watt with the light output luminous flux of 2600 lumens/watt, which was placed slightly above the soil column. Both experiments began by pouring the liquid instantaneously (using the glass funnel with care to avoid damaging the soil surface) onto the top center fractured aggregated soil sample in the acrylic soil column. A volume of $70 \mathrm{ml}$ of distilled water (APL) and toluene (NAPL) were used in samples 1 and 2, respectively. The toluene and water in both experiments were dyed red using Oil-Red-O powder to enhance their visibility during the migration process. After the dyed water and toluene were poured onto the surface area of the fractured soil sample, the first digital image of fluid migration was taken. Subsequent digital images were taken at specific time intervals to capture the fluid migration pattern for both experiments. Sample 1 was recorded for a total of $36 \mathrm{mi}-$ nutes while sample 2 was recorded for 30 minutes based on the total time needed for the liquids to migrate the full depth of the soil column. Using the image acquisition frequency given in Table 2, a total of 115 images and 76 images were produced for sample 1 and 2, respectively.

\subsection{Digital image processing setup}

The digital image processing (DIP) presents the use of computer algorithms to perform image processing on the digital images that have been captured. DIP is a practical technology for classification, pattern recognition, feature extraction, projection, characteristics recognition, image editing, neural networks and multi-scale signal analysis. The recorded colour digital images were saved in JPEG format and transferred from the digital camera to a computer for further image processing using a Matlab routine and Surfer Software. Surfer software can quickly and easily con- vert the Matlab data into outstanding contours, surface, wireframe, vector, image, and post maps. The flow chart of DIP is shown in (Fig. 4).

A Matlab routine for digital image processing was used to extract an area of interest from the captured image and to transform that area of interest from a distorted image to a scale image via the affine transformation method. This involves converting the JPEG scale images to Red Green Blue (RGB) and Hue Saturation Intensity (HSI) images; then extracting the HSI digital value from the HSI image and saving the HSI value in a text file using American Standard Code for Information Interchange (ASCII) format. The Matlab routine coding (C) 2017 Universiti Teknologi Malaysia - All Rights Reserved by "KFLoke.L.m” as shown in (Fig. 5). First, the surfer software was used to digitize the control point from the reference image to extract an actual true scale image coordinate as a control point. The area of interest refers to a pre-determined migration boundary area for samples 1 and 2 that contained the APL and NAPL as shown in (Fig. 6). The Matlab routine was then used to convert the area of interest into RGB and HSI image format, where the values were extracted and saved in ASCII format. The Matlab routine was repeated three times for the subsequent digital image to extract and save the intensity values for all three section areas of interest of the acrylic soil column. The Matlab results were saved in a file along with the summary information of the digital image processing and displayed in the Matlab command window as shown in (Fig. 7). Lastly, a map or plot contour pattern of the migration pattern of APL and NAPL in the fractured porous media using HSI values was generated.

\section{RESULTS}

After the migration process for the top fractured soil surface with the actual size measurement, the column circumference zone was divided to visualize the crack position for sample 1 and 2 as shown in (Fig. 8). Based on the Fig. 8 observation, it can be clearly observed that the soil structure was slightly different in terms of fracture pattern evolution and location of the fracture(s).

The three-dimensional wireframe downward migration pattern of the HSI contour plots of dyed distilled water and toluene in the fractured double-porosity soil sample with $25 \%$ moisture content for samples 1 and 2, respectively, are shown in (Fig. 9). It should be noted that the soil column experiment is practically one dimensional. However, due to random soil fracture, the migration pattern radially is not uniform. To capture this non-uniform migration pattern, the surface of the cylinder is unfolded to a flat 2D plot where the $\mathrm{x}$-axis represent the column circumference while the $y$-axis is the soil depth. 3D wireframes are created by connecting $\mathrm{Z}$ values along lines of $\mathrm{X}$ and $\mathrm{Y}$. A wireframe 3D model is a skeletal representation of the real migration phenomena and is characteristic of a double-porosity soil. The 3D modelling contour plot has a higher quality representation of the liquid migration as compared to a conventional 1D plot. In both samples, $70 \mathrm{ml}$ dyed APL and NAPL were poured instantaneously on the top centre of the soil sample surface to ensure that the dyed APL and NAPL penetrated in one-dimension. In both experiments, the flow of the water and LNAPL migration was not uniformly downward at the front boundary horizontal line due to the inhomogeneity of the fractured double-porosity soil.

In soil sample 1, the selected 3D wireframe HSI plots of dyed distilled water (APL) migration at intervals of 5, 180, 900, and 2160 seconds, respectively, can been seen in (Fig. 9a). Based on the 3D HSI intensity contour plot result, a faster migration oc- 


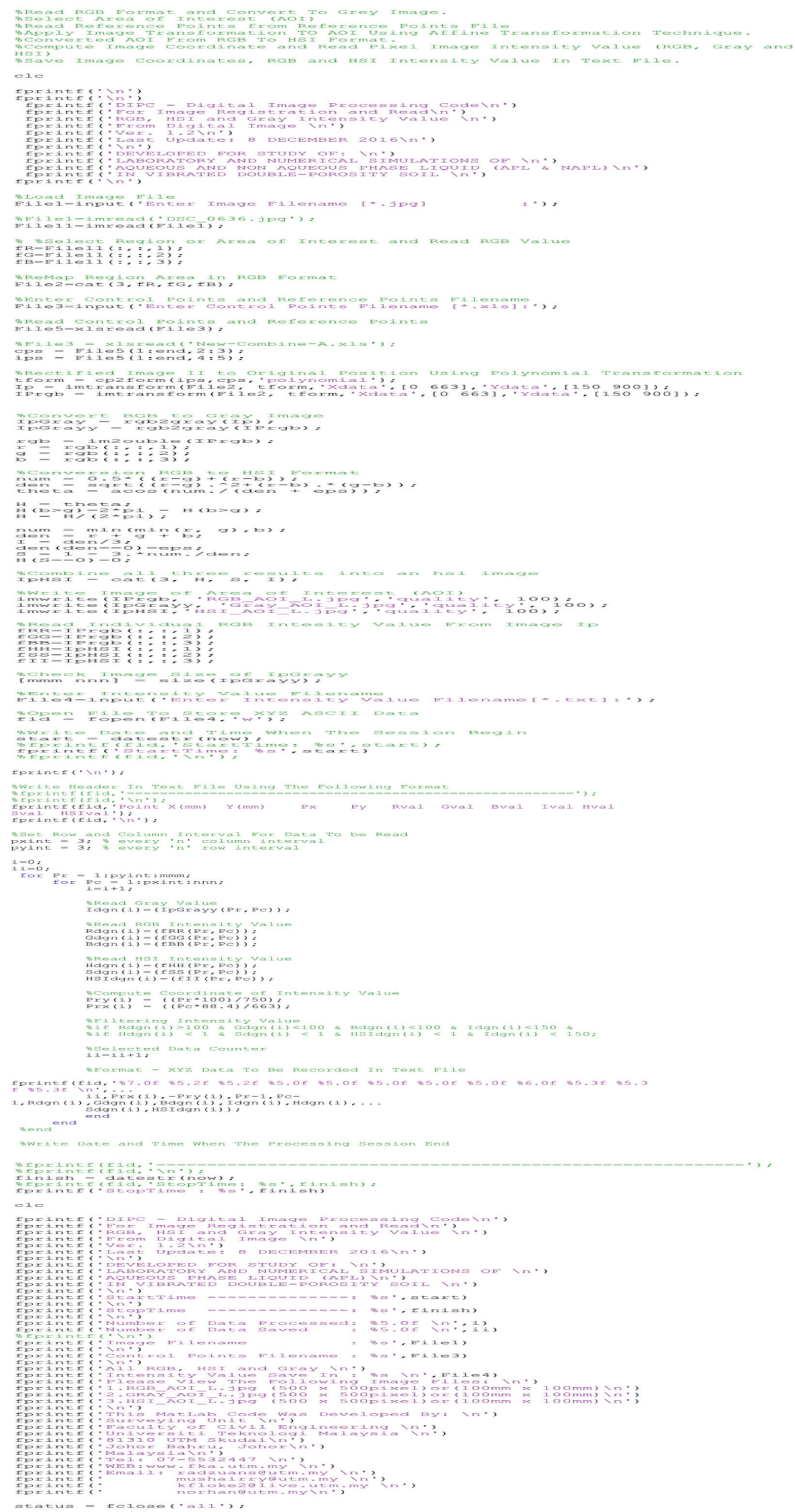




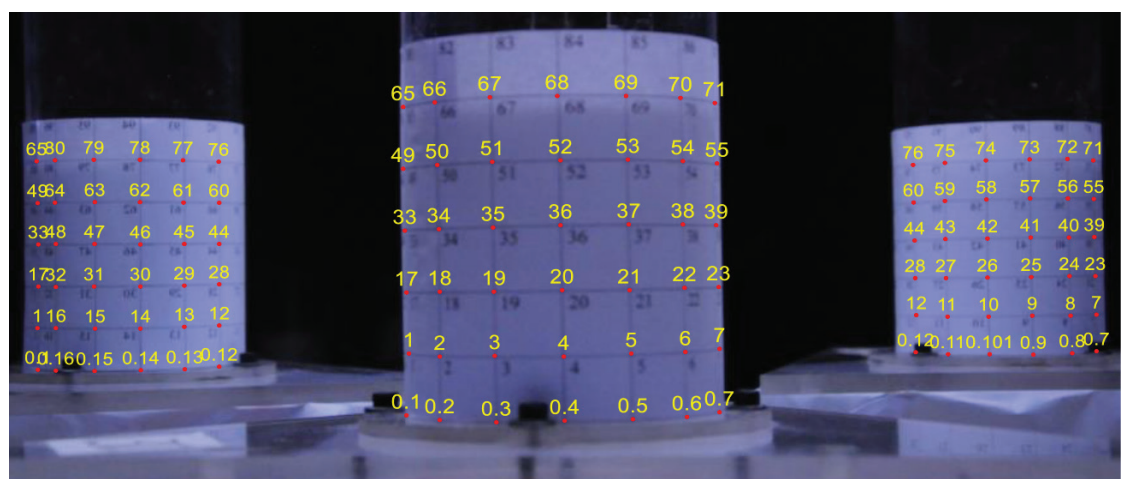

Figure 6. Digitization of the control point for area of interest.

A MATLAB 7.8.0 (R2009a)

File Edit Debug Parallel Desktop Window Help

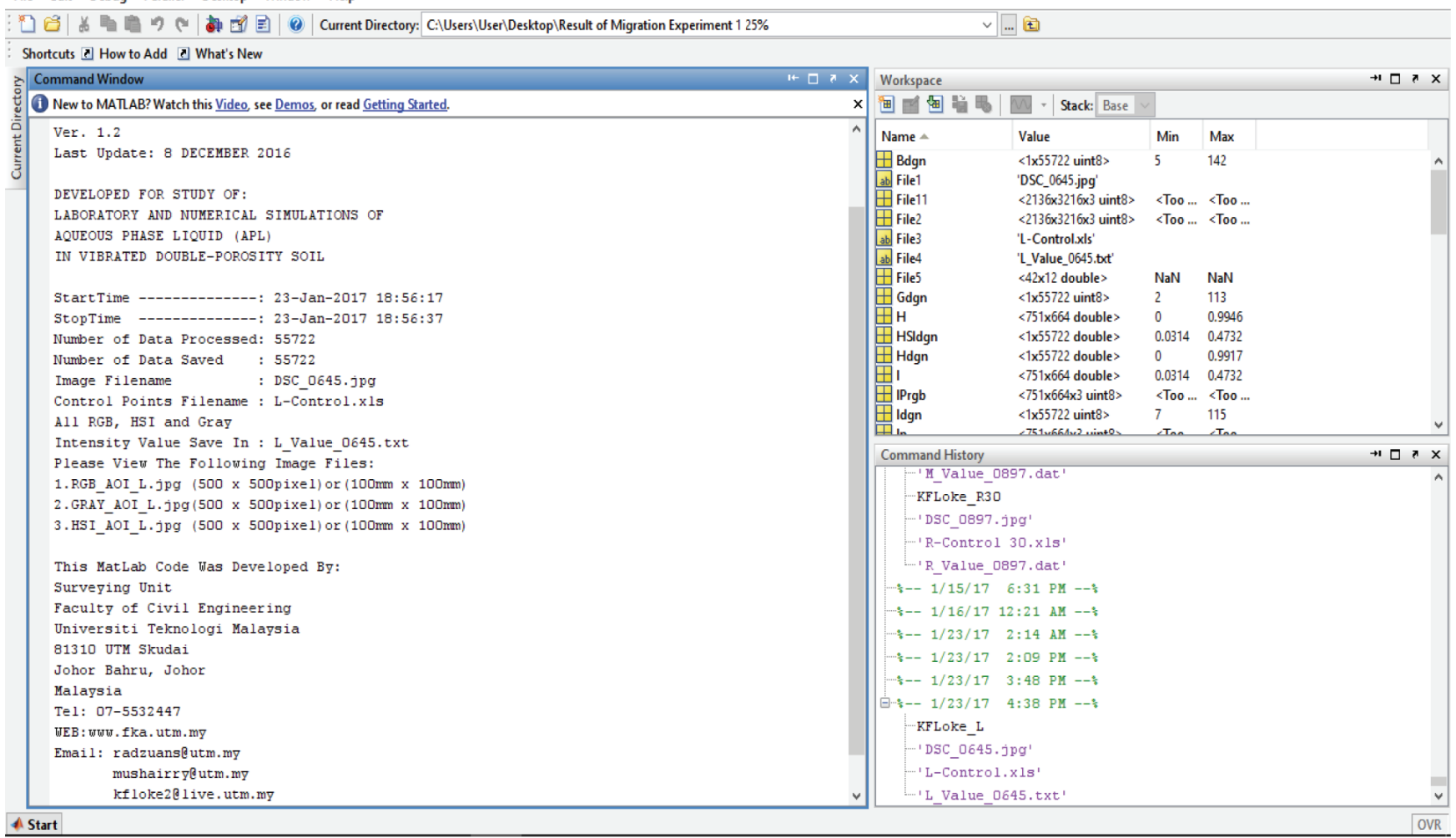

Figure 7. Winding-up summary of the DIP display in the Matlab command window for $L$ section area.
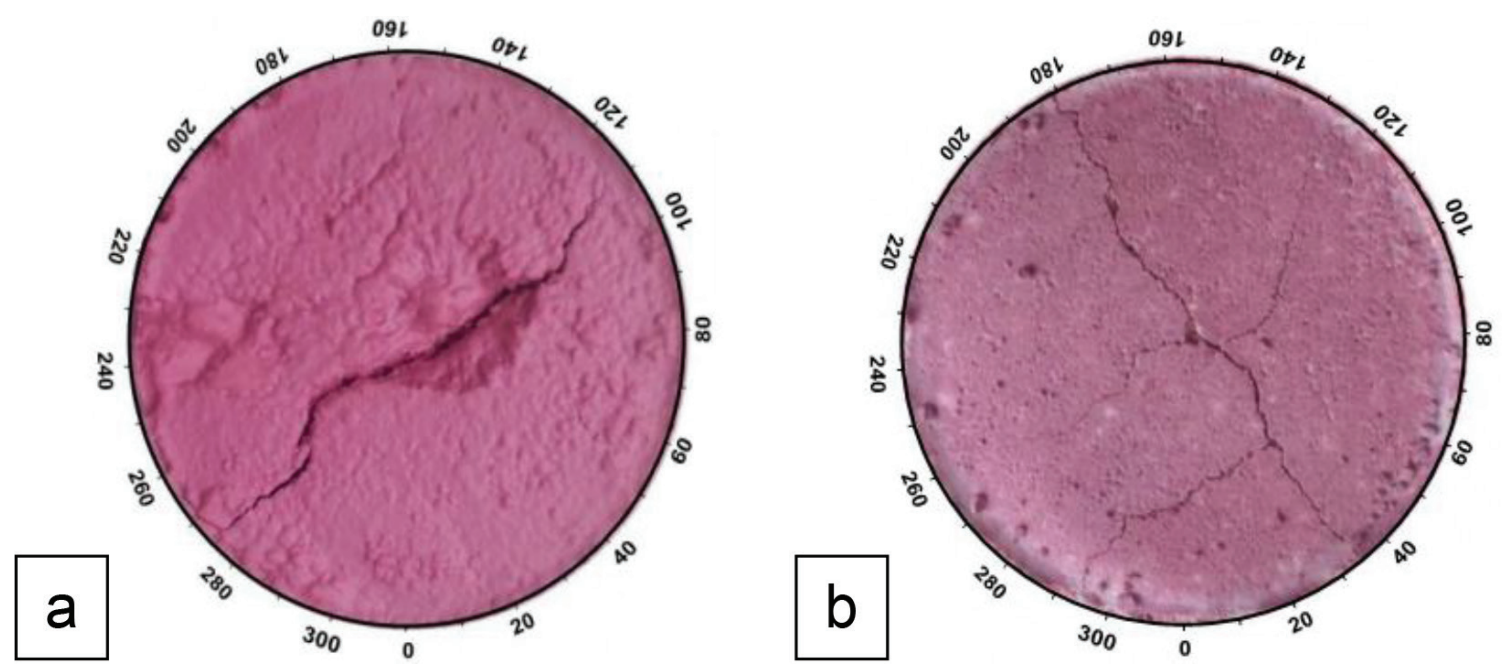

Figure 8. a) Sample 1 (APL). b) Sample 2 (NAPL) migrated soil surface with measurement of actual column circumference zone. 
curred at the cracked soil surface condition as compared to other locations on the soil surface that were not cracked in soil sample 1 as shown in (Fig. 8a). The dyed water completely migrated over the whole top soil surface area into the fractured soil sample of the test, which took approximately 360 seconds. Meanwhile, the duration for the dyed water migration from the top surface to the stop point was 2160 seconds and further observations at 3600 seconds indicated that no further changes in migration pattern had occurred where the APL migration between 90 to $150 \mathrm{~mm}$

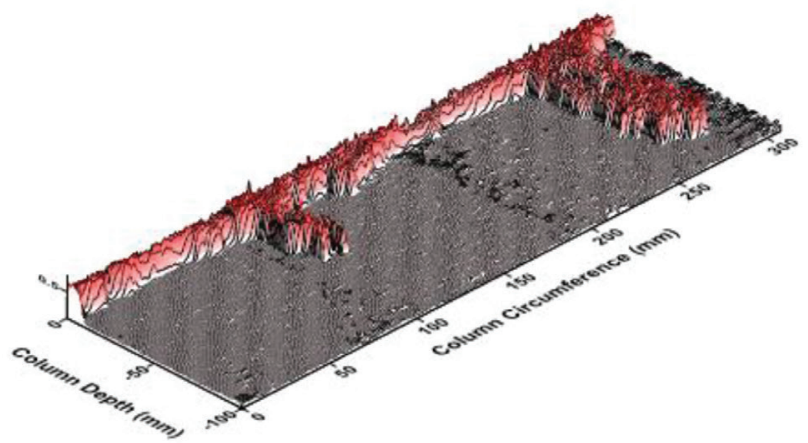

(5 seconds)

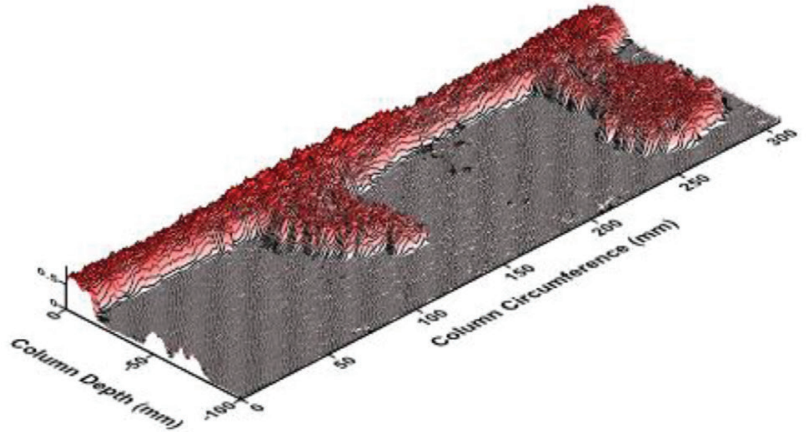

(180 seconds)

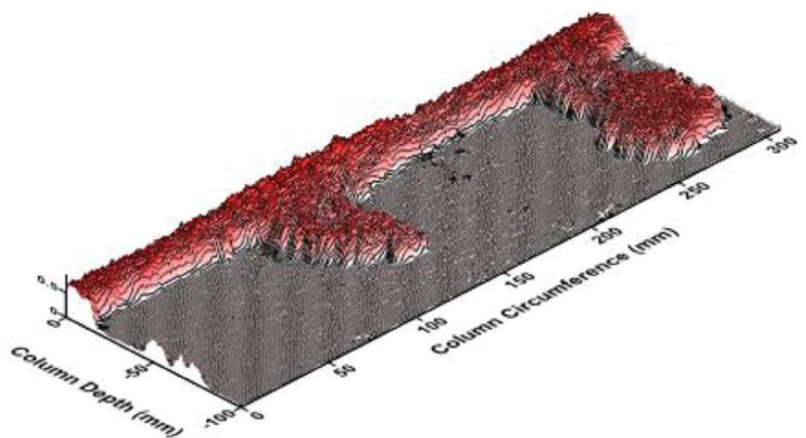

(900 seconds)

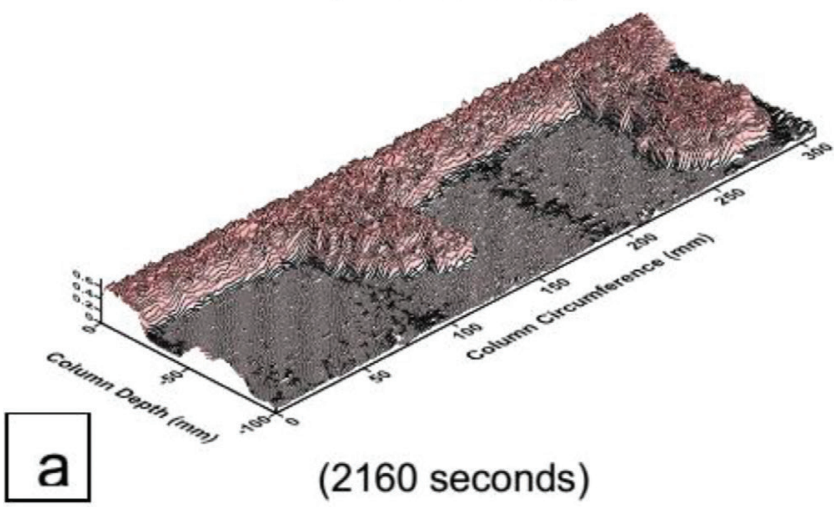

along the $\mathrm{x}$-axis had migrated downward approximately $92 \%$ of the soil sample depth. After 5 seconds, the dyed APL had penetrated nearly halfway through the soil sample at the location of the fractured soil surface, as shown in Fig. 9a. The deepest APL downward migration depth along the soil column was $92 \mathrm{~mm}$ of the total length of the $100 \mathrm{~mm}$ soil sample. The dyed distilled water (APL) migration stopped at 2160 seconds and did not fully migrate in this study because the water viscosity was 0.00089 $\mathrm{kg} / \mathrm{m} / \mathrm{s}$, while toluene viscosity was $0.00055 \mathrm{~kg} / \mathrm{m} / \mathrm{s}$, a viscosity

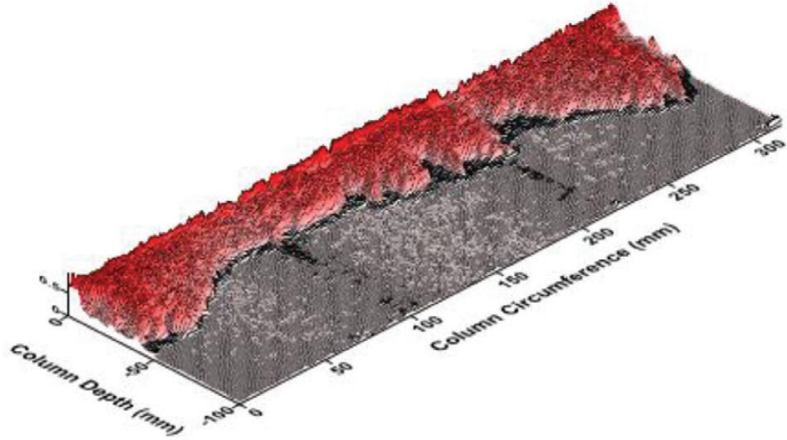

(5 seconds)

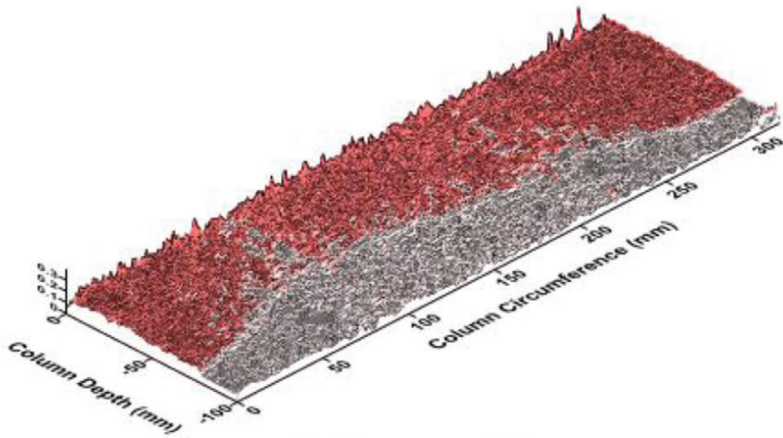

(180 seconds)

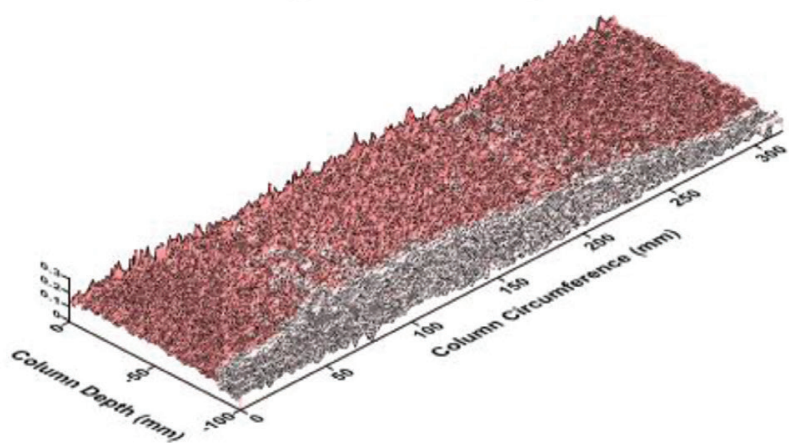

(900 seconds)

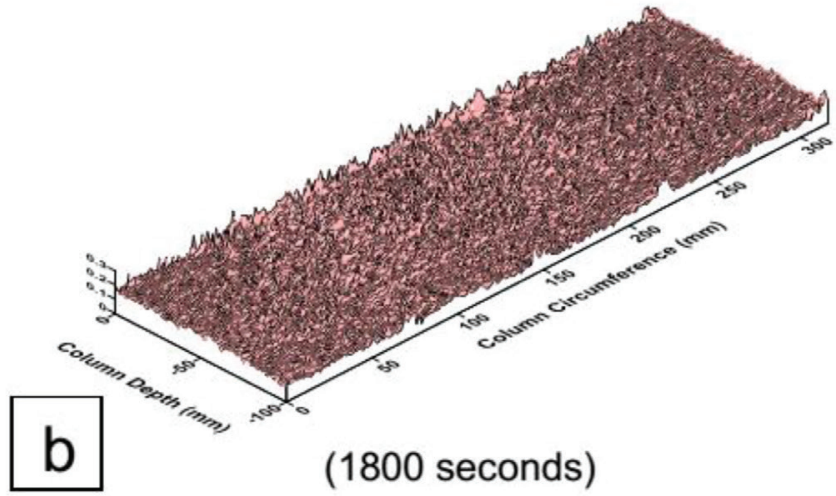

Figure 9. a) Sample 1 (APL). b) Sample 2 (NAPL) 3D wireframe HSI plots of downward migration in fracture double-porosity soil. 


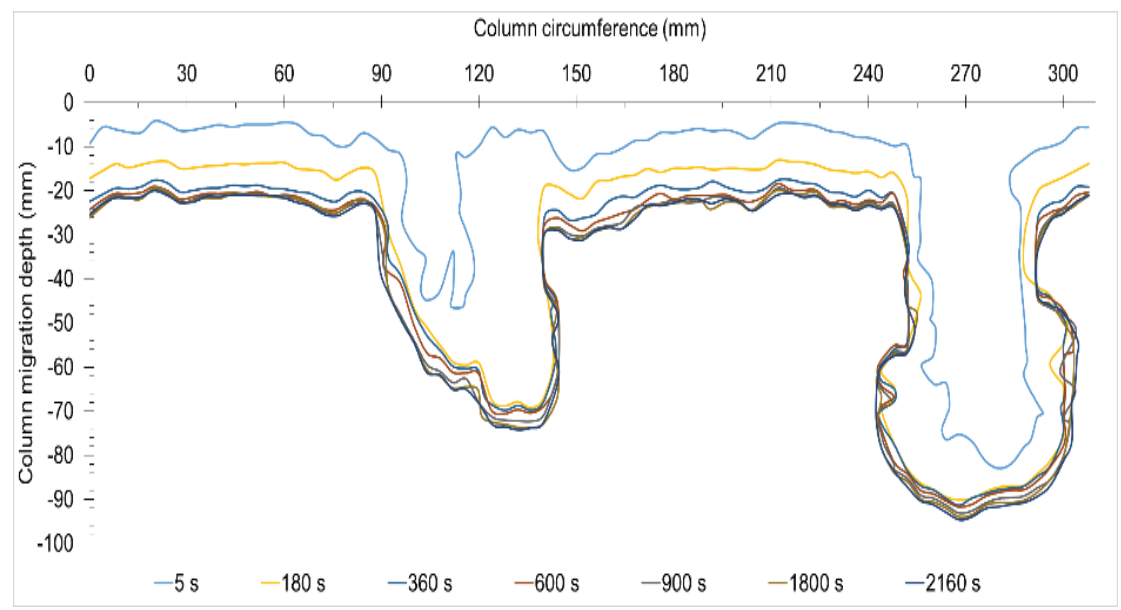

Figure 10. Measured values of APL migration depth as a function of the column circumference zone for selected critical time interval in seconds.

difference of about 38\% (ASSAEL et al., $2001 \&$ JOSEPH at al., 1978). Thus, the dyed water caused the highest resistance and friction to gradual migration.

In soil sample 2, intervals of 5, 180, 900 and 1800 seconds, respectively, were selected for the 3D wireframe dyed NAPL migration HSI contour plots as shown in Fig. 9b. The NAPL migration was similar to the results found in sample 1. After 5 seconds, the dyed NAPL migration reached nearly halfway through the test sample at the location of the fractures in the soil surface as shown in Fig. 8b. The LNAPL completely receded from view over the whole top soil surface area into the fractured soil sample of the test, which took about 5 seconds. Meanwhile, the overall duration for dyed water migration from the top surface to the bottom of the soil column was 1800 seconds and a further observation at 3600 seconds showed no changes in migration pattern where the NAPL migration fully reached the bottom of the soil column.

The migration observation of sample 1 shows that the NAPL migration in sample 2 reached $100 \%$ of the soil column depth, but in contrast, the dyed water migration was the slower migration and did not fully reach the bottom of the soil column because water has a higher viscosity as compared to toluene. This could also be because the physical bonding between toluene and soil is weaker than that between water and soil. The physical bonding between toluene and soil was attributed to Van Der Waals Forces, which are weaker than hydrogen bonding, which has stronger physical bonding between water and soil. This was also one of the reasons why the water (APL) migration was slower than for the toluene (NAPL) migration. In previous research by SA'ARI et al. (2015), an experiment on toluene migration in a double-porosity soil with $25 \%$ moisture content without vibration effect was performed, and the results showed that the toluene NAPL migration to the bottom took 2280 seconds compared to this study, where NAPL and APL migration took only approximately 1800 seconds and 2160 seconds, respectively, to reach the bottom of the soil column. This could be because the fracture that occurred at double-porosity loosened the soil structure in this study as compared to previous research migration in intact double-porosity that has a stronger and more compact soil structure. Thus, this study supported the previous research by LOKE et al. (2017), which stated that the specific fractured double-porosity soil experienced a faster migration compared to the intact double-porosity soil.

The measured values of dyed APL and NAPL migration, as a function of the column circumference, for the selected critical time interval in seconds are shown in Figs. 10 and 11 for samples

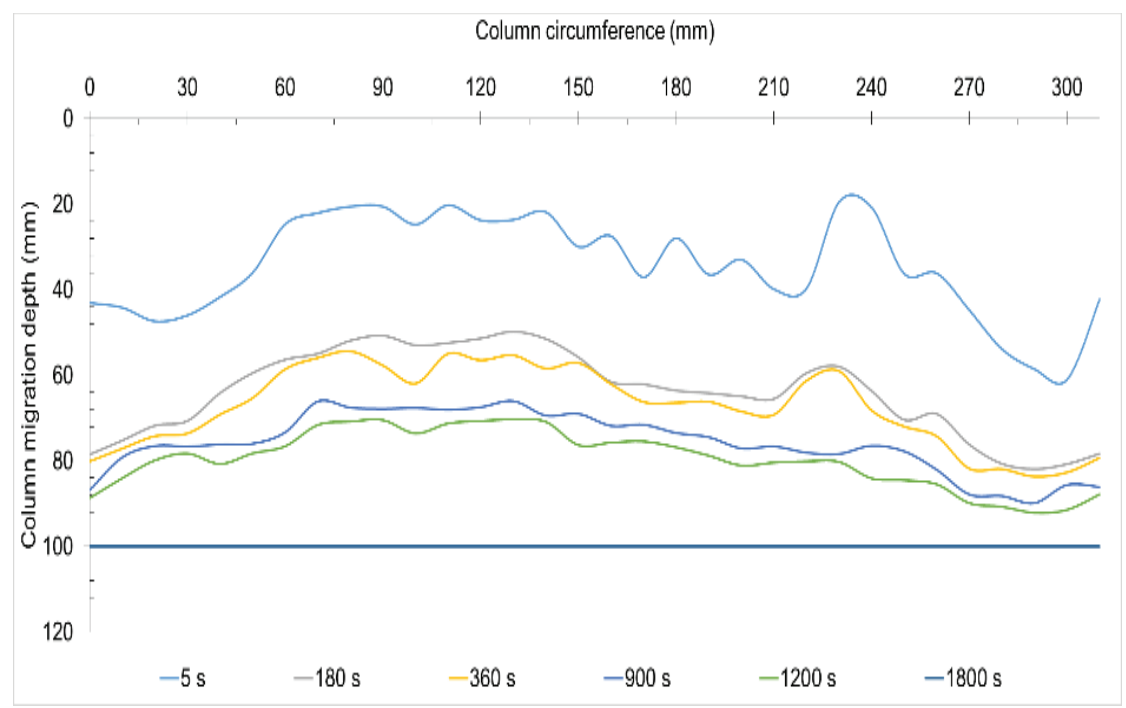

Figure 11. Measured values of NAPL migration depth as a function of the column circumference zone for selected critical time interval in seconds. 
Table 3. Migration speed rate for every $30 \mathrm{~mm}$ column circumference.

\begin{tabular}{|c|c|c|c|c|}
\hline \multirow{3}{*}{$\begin{array}{l}\text { Column Circum- } \\
\text { ference Zone } \\
(\mathrm{mm})\end{array}$} & \multicolumn{4}{|c|}{ Migration Speed Rate $(\mathrm{mm} / \mathrm{s})$} \\
\hline & \multicolumn{2}{|c|}{ Soil sample 1 (APL) } & \multicolumn{2}{|c|}{ Soil sample 2 (NAPL) } \\
\hline & $\begin{array}{l}\text { Higher Flow } \\
\text { Between Initial } \\
\text { to } 30 \text { Seconds }\end{array}$ & $\begin{array}{l}\text { Average Flow } \\
\text { for All the Time } \\
\text { Interval }\end{array}$ & $\begin{array}{l}\text { Higher Flow } \\
\text { Between Initial } \\
\text { to } 30 \text { seconds }\end{array}$ & $\begin{array}{c}\text { Average Flow } \\
\text { for All the Time } \\
\text { Interval }\end{array}$ \\
\hline 0 & 0.31 & 0.05 & 2.87 & 0.49 \\
\hline 30 & 0.21 & 0.04 & 2.30 & 0.40 \\
\hline 60 & 0.15 & 0.04 & 1.65 & 0.30 \\
\hline 90 & 0.36 & 0.10 & 1.37 & 0.26 \\
\hline 120 & 0.33 & 0.19 & 1.58 & 0.29 \\
\hline 150 & 0.49 & 0.07 & 2.00 & 0.35 \\
\hline 180 & 0.23 & 0.04 & 1.86 & 0.33 \\
\hline 210 & 0.16 & 0.04 & 2.66 & 0.47 \\
\hline 240 & 0.27 & 0.05 & 1.38 & 0.25 \\
\hline 270 & 2.80 & 0.28 & 2.80 & 0.49 \\
\hline 300 & 0.29 & 0.05 & 4.07 & 0.69 \\
\hline
\end{tabular}

1 and 2, respectively. Based on the results in Fig. 10, the fastest and most critical migration downward depth of APL migration occurred between 90 to $140 \mathrm{~mm}$ and 240 to $280 \mathrm{~mm}$ along the soil column circumference within 5 seconds as demonstrated by the steep gradient of the graph within that duration. The significant difference is due to the condition of the fractured soil surface, compared to other locations on the soil surface, which were not fractured. Meanwhile, the rest of the column circumference positions continue a slow, decreased migration from the start until the end of the experiment.

Based on the results shown in Fig. 11, it was found that the cumulative migration depth of NAPL migration between 0 to $30 \mathrm{~mm}$ and $260 \mathrm{~mm}$ to $310 \mathrm{~mm}$ along the column circumference, displayed the most critical migration downward within 5 seconds as shown by the steepest gradient on the graph within that duration. The NAPL migration sped up between 5 and 180 seconds, which shows a difference in the migration pattern. The speeding up of the NAPL is caused by high entry pressure at the top soil surface due to the weight of the liquid. Meanwhile, the remaining column circumference positions displayed a slight decrease in NAPL migration from the start until the end of the experiment.

The calculated migration speed rate for the higher and overall average speed for every $30 \mathrm{~mm}$ column circumference zone is demonstrated in Table 3. Sample 1 shows the higher migration speed rate from the start to 30 seconds was at the $270 \mathrm{~mm}$ column circumference zone with a migration speed rate of $2.80 \mathrm{~mm} / \mathrm{s}$. The overall average dyed water (APL) migration rate for sample 1 is $0.09 \mathrm{~mm} / \mathrm{s}$. Sample 2 displays the higher migration rate from initial to 30 seconds at $300 \mathrm{~mm}$ column circumference zone, with a migration speed of $4.07 \mathrm{~mm} / \mathrm{s}$. Meanwhile, the overall average dyed toluene (NAPL) migration rate for sample 2 is $0.39 \mathrm{~mm} / \mathrm{s}$. This value is higher compared to the non-fractured soil condition (SA'ARI et al., 2015). For both samples, the higher migration flow occurred at the column circumference position that displayed the larger fractured soil structure.

\section{CONCLUSIONS}

A physical laboratory experiment on APL and NAPL migration in a fractured double-porosity soil with $25 \%$ moisture content has been carried out. This laboratory experiment was intentionally designed to investigate and differentiate between the APL and NAPL migration characteristics and patterns in the fractured double-porosity soil placed in an acrylic circular soil column. The digital image processing technique using the Matlab routine and Surfer software was applied to extract and analyse the APL and NAPL migration data acquired from captured digital images. From the results observed, both experiments indicated that in comparison to the APL migration, the NAPL migrated faster from the top surface to the bottom of the soil column. The significant finding was that the NAPL had fully migrated to the bottom $(100 \%)$, but the APL migration stopped at $92 \%$ of the soil column depth. Liquid migration was observed to be faster for the fractured soil condition. This is because this study applied the effect of vibration on the double-porosity and the additional capillary force exerted by the fluid pressure on top of the fractured soil sample. From the results, it can be concluded that the factors that significantly influenced the APL and NAPL migration in samples 1 and 2, respectively, were the structure of the soil sample, the fracture pattern of the soil sample, viscosity of the liquid, physical interaction bonding between the liquid and the soil sample, and the capillary pressure of the fluid. In conclusion, this study indicates that the fractured double-porosity soil under a vibration effect with NAPL migration has very detrimental consequences for groundwater resources. The current model makes a more practicable contribution to future sustainable groundwater protection and remediation.

\section{ACKNOWLEDGEMENT}

This study was supported by the Research Management Centre (RMC), Universiti Teknologi Malaysia under Research University Grant - Tier 1 (PY/2016/06547) from the Ministry of Higher Education, Malaysia. The authors would also like to thank their respective University, Public Service Department Malaysia, Geotechnical Laboratory, Hydraulic and Hydrology Laboratory, Engineering Seismology and Earthquake Engineering Research Group (eSEER), and Survey Unit, Faculty of Civil Engineering, Universiti Teknologi Malaysia for their kind assistance in this research. The first author was supported through the federal training award by the Public Service Department under Prime Minister's Department, Malaysia.

\section{REFERENCES}

ALAZAIZA, M.Y.D., NGIEN, S.K., BOB, M.M., KAMARUDDIN, S.A. \& ISHAK, W.M.F. (2017): Influence of macro-pores on DNAPL migration in double-porosity soil using light transmission visualization method.- Transport in Porous Media, 117, 103-123. doi:10.1007/s11242-017-0822-3

ASSAEL, M.J., AVELINO, H.M.T., DALAOUTI, N.K., FARELEIRA, J.M.N.A. \& HARRIS, K.R. (2001): Reference correlation for the viscosity of liquid toluene from 213 to $373 \mathrm{k}$ at pressures to $250 \mathrm{Mpa}$.- International Journal of Thermophysics, 22/3, 789-799. doi:10.1023/A:1010774932124

BAGHERIEH, A.R., KHALILI, N., HABIBAGAHI, G. \& GHAHRAMANI, A. (2009): Drying response and effective stress in a double porosity aggregated soil.- Engineering Geology, 105/1-2, 44-50. doi:10.1016/j.enggeo.2008.12.009

BOB, M.M., BROOKS, M.C., MRAVIK, S.C. \& WOOD, A.L. (2008): A modified light transmission visualization method for DNAPL saturation measurements in 2-D models.- Advance Water Resource, 31, 727-742. doi:10.1016/j.advwatres.2008.01.016

BRIDGE, J.W., BANWART, S.A. \& HEATHWAITE, A.L. (2006): Non-invasive quantitative measurement of colloid transport in mesoscale porous media using image lapse fluorescene imaging.- Environment Science Technology, 37, 1859-1868. doi:10.1021/es0603731

CARMINATI, A., KAESTNER, A., LEHMAN, P. \& FLÜHLER, H. (2008): Unsaturated water flow across soil aggregate contacts.- Advances in Water Resources, 31/9, 1221-1232. doi:10.1016/j.advwatres.2008.01.008

CNUDDE, V. \& BOONE, M. (2013): High-resolution X-ray computed tomography in geosciences : A review of the current technology and applications.- Earth Science Reviews, 123, 1-17. doi:10.1016/j.earscirev.2013.04.003

EL-ZEIN, A., CARTER, J.P. \& AIREY, D.W. (2006): Three-dimensional finite elements for the analysis of soil contamination using a multiple-porosity approach.- International Journal for Numerical and Analytical Methods in Geomechanics, 30/7, 577-597. doi:10.1002/nag.491

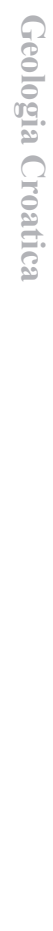


FEDERAL EMERGENCY MANAGEMENT AGENCY, FEMA 461 (2007): Interim testing protocols for determnining the seismic performance characteristics of structural and nonstructural components.-Applied Technology Council, Redwood City, California.

FREDLUND, D.G., HOUSTON, S.L., NGUYEN, Q. \& FREDLUND, M.D. (2010): Moisture movement through cracked clay soil profiles.- Geotechnical and Geological Engineering, 28/6, 865-888. doi:10.1007/s10706-010-9349-x

HARITH, N.S.H.,ADNAN, A. \& SHOUSHTARI, A.V. (2017): Deaggregation of probabilistic ground motions in the Kota Kinabalu and Lahad Datu Towns of Sabah, Malaysia.- MATEC Web of Conferences. Seoul, South Korea, 09001, 2-11. doi:10.1051/matecconf/201713809001

JOSEPH, K., MORDECHAI, S. \& WILLIAM, A.W. (1978): Viscosity of liquid water in the range $8^{\circ} \mathrm{C}$ to $150^{\circ} \mathrm{C}$.- Journal Phys. Chem. Ref. Data, 7/3, 941-948. doi:10.1063/1.555581

KECHAVARZI, C., SOGA, K., ILLANGASEKARE, T.H. \& NIKOLOPOULOS, P. (2008): Laboratory study of immiscible contaminant flow in unsaturated layered sands.- Vadose Zone Journal, 1-9. Doi: 10.2136/vzj2006.0177

KRISNANTO, S., RAHARDJO, H., FREDLUND, D.G. \& LEONG, E.C. (2014): Mapping of cracked soils and lateral water flow characteristics through a network of cracks.- Engineering Geology, 172, 12-25. doi:10.1016/j.enggeo.2014.01.002

LAKELAND, D.L., RECHENMACHER, A. \& GHANEM, R. (2014): Towards a complete model of soil liquefaction: the importance of fluid flow and grain motion.Proceedings of the Royal Society A - Mathematical, Physical and Engineering Sciences, London A470:20130453. doi:10.1098/rspa.2013.0453

LEWANDOWSKA, J., SZYMKIEWICZ, A., GORCZEWSKA, W. \& VAUCLIN, M. (2005): Infiltration in a double-porosity medium: Experiments and comparison with a theoretical model.- Water Resources Research, 41/2, W02022. doi:10.1029/2004WR003504

LI, X. \& ZHANG, L.M. (2009): Characterization of dual-structure pore-size distribution of soil.- Canadian Geotechnical Journal, 46, 129-141. doi: 10.1139/T08-110

LOKE, K.F., RAHMAN, N.A. \& NAZIR, R. (2017): Experimental study on unsaturated double-porosity soil phenomena under vibration effect.- Jurnal Teknologi, 79/4, 65-72. doi:10.11113/jt.v79.9976

LOKE, K.F., RAHMAN, N.A. \& RAMLI, M.Z. (2016): A laboratory study of vibration effect for deformable double-porosity soil with different moisture content.- Malaysian Journal of Civil Engineering, 28, SI/3, 207-222.

LUCIANO, A., VIOTTI, P. \& PAPINI, M.P. (2010): Laboratory investigation of DNAPL migration in porous media.- Journal of Hazardous Materials, 176, 1006-1017. doi:10.1016/j.jhazmat.2009.11.141
MAJA, I., NEDA, V., SANDRA, D.B.B., VLADIMIR, B. \& IVAN, S. (2015): Mineralogy, surface properties and electrokinetic behaviour of kaolin clays derived from naturally occurring pegmatite and granite deposits.-Geologia Croatica, 68/2, 139145. doi: $10.4154 / \mathrm{gc} .2015 .09$

MASCIOPINTO, C., BENEDINI, M., TROISI, S. \& STRAFACE, S. (2001): Conceptual models and field test results in porous and fractured media in groundwater pollution control.- WIT Press, Southampton, UK.

NGIEN, S.K., CHIN, P.Q., HASAN, M., ALI, M.I., TADZA, M.Y.M. \& RAHMAN, N.A. (2016): Image analysis of non-aqueous phase liquid migration in aggregated kaolin.- ARPN Journal of Engineering and Applied Sciences, 11/10, 6393-6398.

NGIEN, S.K., RAHMAN, N.A., AHMAD, K. \& LEWIS, R.W. (2012): A review of experimental studies on double-porosity soils.-Scientific Research and Essays, 7/38, 3243-3250. doi:10.5897/SRE11.2131

NGIEN, S.K., RAHMAN, N.A., BOB, M.M., AHMAD, K., SA'ARI, R., \& LEWIS, R.W. (2011): Observation of light non-aqueous phase liquid migration in aggregated soil using image analysis.- Transport in Porous Media, 92/1, 83-100. doi: 10.1007/s11242-011-9892-9s

PENG, Z., DUWIG, C., DELMAS, P., GAUDET, J.P., STROZZI, A.G., CHARRIER, P. \& DENIS, H. (2015): Visualization and characterization of heterogeneous water flow in double-porosity media by means of X-ray computed tomography.- Transport in Porous Media, 110, 543-564. doi:10.1007/s11242-015-0572-Z

SA`ARI, R., RAHMAN, N.A., LATIF ABDUL, N.H., YUSOF, Z.M., NGIEN, S.K., KAMARUDDIN, S.A., MUSTAFFAR, M. \& HEZMI, M.A. (2015): Application of digital image processing technique in monitoring LNAPL migration in double porosity soil column.- Jurnal Teknologi, 3/72, 23-29. doi:10.11113/jt.v72.4018

SEONG, K.P. (2005): Sustainable mining of the clay resources in peninsular Malaysia.- Geological Society of Malaysia Bulletin, 51, 1--5.

SITTHIPHAT, E.A. \& SIAM, Y. (2016): Investigation of average optical density and degree of liquids saturation in sand by image analysis method.- KKU Eng. Journal, 43/S1, 147-151. doi:10.14456/kkuenj.2016.44

YOUSEF, H.N., NASSIR, S.N.A.A., MUHAMMAD, K.J., HOSSAM, A.K., HABES, G., MAHMOUD, M.E.W., AWNI, B. \& TAISSER, Z. (2015): Multivariate statistical analysis of urban soil contamination by heavy metals at selected industrial locations in the greater Toronto area, Canada.- Geologia Croatica, 68/2, 147-159. doi:10.4154/gc.2015.10

ZHENG, F., GAO, Y., SUN, Y., SHI, X., XU, H. \& WU, J. (2015): Influence of flow velocity and spatial heterogeneity on DNAPL migration in porous media: Insights from laboratory experiments and numerical modelling.- Hydrogeology Journal, 23, 1703-1718. doi:10.1007/s10040-015-1314-6 